\title{
CEREBRAL DOMINANCE IN CASES OF READING DISABILITY
}

\author{
BY \\ J. McFIE* \\ From the National Hospital, Queen Square, London
}

In an extensive review of the literature on reading disability Hallgren (1950) finds a consensus of opinion among most authors that the incidence of severe cases of dyslexia among otherwise normal school-children is about $1 \%$; and this agrees well with the most recent finding in this country, reported in the Ministry of Education (1950) pamphlet "Reading Ability", that $1.4 \%$ of children leaving school were illiterate. Hinshelwood (1917) described individual cases of this disability under the designation "congenital word blindness", but it was Orton (1937) who attracted attention to the disturbances of lateral dominance in the patients he studied. (I am inclined to subscribe to Orton's and Hallgren's criticism of this term, and to agree with the latter that the diagnosis " specific dyslexia" is suitably obscure, adequately descriptive, and carries no theoretical implications.)

Orton observed that hand or eye preferences were often not consistently unilateral; and set up the hypothesis that

"the existence of demonstrable mixtures between right and left motor preferences ... implies that comparable intergrading may exist between the critical areas for the various fractions of the language faculty in the two hemispheres of the brain, thus giving rise to a series of developmental disorders in language" (1937). These disorders arise because

"learning to read .... entails the elision of one of the two antitropic records or engrams (in opposite hemispheres), and faulty or incomplete elision would result in uncertainty in mnemonic recall of orientation and progression" (1943).

Subsequently, a number of investigations has been reported of the lateral preferences of dyslexic children, the evidence in some cases supporting, and in others opposing, Orton's interpretation. Although not confirmed by Hallgren's investigation, perhaps the most consistent observation has been that a high proportion of these patients show a left-eye preference (Macmeeken, 1939) or cross dominance, right-handed but left-eyed (Harris, 1947). Some authors (e.g. Wile, 1942 ; Blau, 1946) contend that right-eye dominance is more conducive to the left-

* Joint holder of the Pinsent-Darwin Studentship in Mental Pathology, Cambridge University. to-right direction of gaze necessary in reading; while Orton (1943) considered " that left-eyedness is not the cause of the reading disability but rather indicates that there is present in these persons a tendency toward use of the right hemisphere of the brain-i.e. leftsidedness ". Selzer (1933), on the other hand, found that, of a group of normal children, the left-eyed tended to be faster readers.

It is difficult, however, in view of the bilateral projection of each retina upon the cerebral hemispheres, to see how the demonstration of ocular preference can indicate the dominance of either hemisphere. It is more relevant in this connexion to study the " preference" for one or other of the homonymous half-fields; but here again different methods of investigation have produced conflicting results. Stevens and Ducasse (1912) found that their (right-handed) subjects tended to overestimate extents in the right half-field of vision ; White and Dallenbach (1932) that for right-handed subjects the left half-field had greater "attention value" and the right for left-handers ; and LaGrone and Holland (1943) found an association between righthandedness, right-eyedness, preference for the left half-field, and higher reading ability.

The present study concerns the use of the Phi Test of lateral dominance in visual function, described by Jasper and Raney (1937), in which a comparison is made of the extent to which the phenomenon of apparent movement ("phi") is seen in the two half-fields of vision. Examining a group of normal school-children with this procedure, Jasper and Raney found a close agreement between the hemispheral dominance indicated by the test and by subjects' handedness, and the present investigation was undertaken in the expectation that results might support, or otherwise, Orton's view that specific dyslexia " has its neurological basis in confusion in cerebral dominance" (1942). Jasper had earlier (1932) found that seven out of 19 stutterers saw no apparent movement on this test, and concluded that

" unilaterality in general neural organisation is expressed in the field of perception as well as in the 


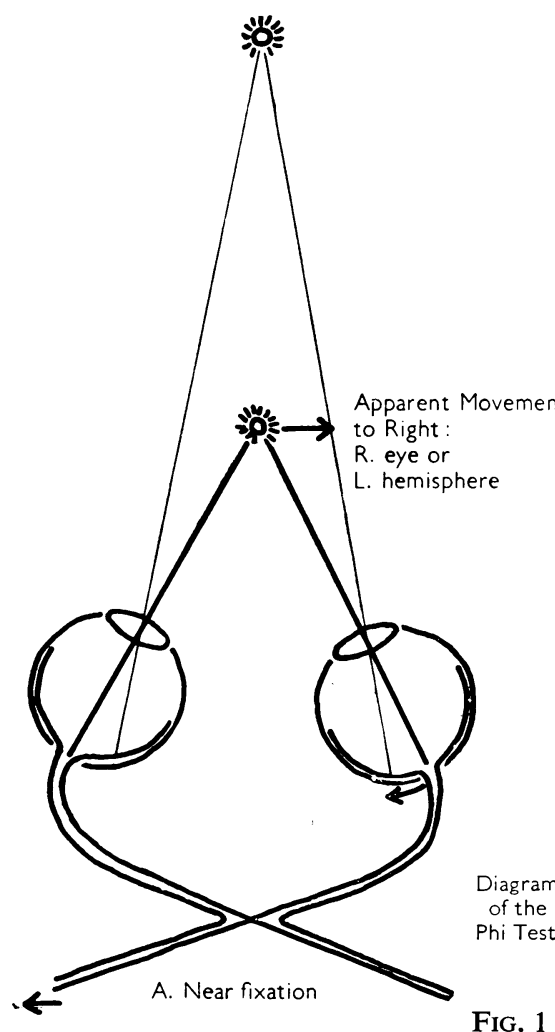

FIG. 1

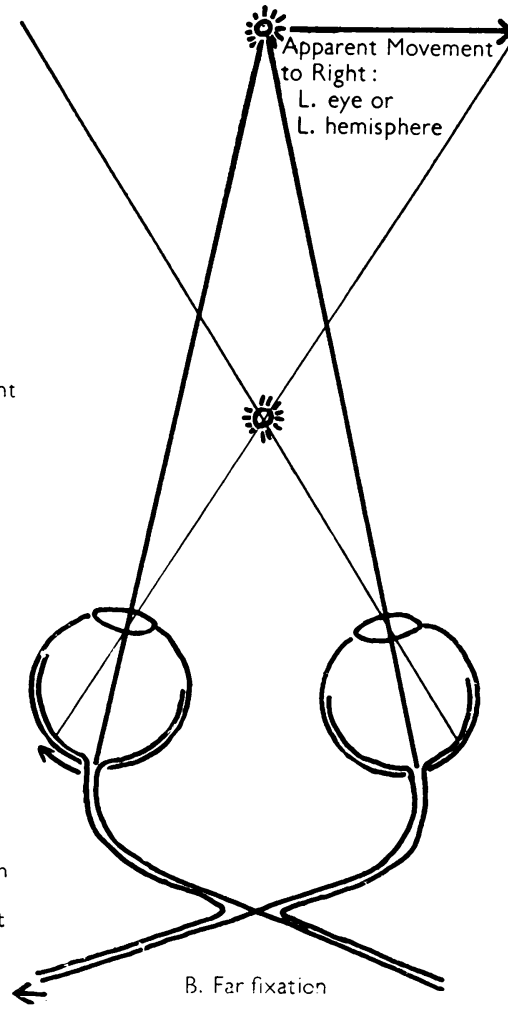

light and the near light are being fixated, it is possible to deduce whether the apparent movement is a function of eyedominance or of "hemispheredominance". Fig. 1 shows the relationships involved in the two positions of fixation.

The apparatus consisted simply of a long, light-tight box, in which the near point of light was 10 in. from the viewing-slot and the far one 60 in. The lights were alternately illuminated, as in Jasper and Raney's apparatus, by a commutator driven by a variable speed gramophone motor. The subject was required to fixate the near light, and then to look at the alternation between this and the side-lights, until he reported consistent apparent movement lasting two minutes, or for 10 minutes, whichever was the shorter time. The time intervals of illumination were then changed and the experiment repeated with the far light as

field of manual preference. The .... test . . clearly demonstrated the lack of unilaterality on the part of stutterers as compared with right- and left-handed normal speakers."

\section{Testing Procedures}

The Phi Test.-The essential feature of this test consists of the exposure of a small point of light, which the subject fixates, which is extinguished and followed after an interval of 80 to $100 \mathrm{~m}$.secs. by the appearance of two points of light, one on either side of the line of fixation ; these are extinguished and the central point again illuminated; and the cycle is repeated until the subject reports apparent movement of the central light toward one of the side-lights. A consideration of the neuro-anatomical relations of the retinae makes it clear that the perception of apparent movement from the fixation point to one of the side lights must involve the visual pathway of the opposite hemisphere. An additional advantage of Jasper and Raney's procedure is that, as there are in fact only two points of light, alternately illuminated, and the "side-lights" are actually the double images formed by the nonfixated light, there are two possibilities for fixation ; and, by comparing the subject's report when the far fixation point In each case, the direction of movement, if reported, was checked by requiring the subject to indicate it on a diagram of the three points of light

Handedness.-As Blau (1946) and Burt (1950) have pointed out, hand preference is more consistent, and for the majority of subjects more frequently rightsided, the greater the skill involved in the operation. Since the present study is concerned specifically with language functions, it was thought that hand preference in relation to these functions would be the most relevant criterion : this was determined simply by requiring the subject to write simultaneously with both hands the numbers from 1 to 10 while keeping his eyes closed (Harris, 1947), and noting the hand showing the better coordination.

Eye-preference.-Buxton and Crosland (1937) have demonstrated the reliability of simple tests of ocular preference. In the present study it was determined by requiring the subject to look, through a hole in a card held in both hands about a foot from his nose, at an object to his left, to his right, and to his left. If there was any variation in the eye used, three more observations (right, left, right) 
were made, and the eye most frequently used was noted. To determine the possible relevance of " direction of gaze" some subjects were also shown a reproduction of Jastrow's (Fig. 2) ambiguous figure (Blau, p. 134) and asked what it looked like to them.

Intelligence. - Intelligence was tested on eight of the 11 items of the Wechsler-Bellevue adult scale,* and visual retention with the Stanford-Binet Form L " memory for designs" item.

Reading Ability.-This was tested quantitatively on Burt's (1947) Scholastic Test 1 and qualitatively on Schonell's (1948) Diagnostic Tests R6 and R7. Writing (spelling) was tested on Burt's Scholastic Test 6.

\section{Case Histories}

Case 1 (N.H.2003).—A packer, aged 17, was first seen four years ago, on account of reading disability. He is one of eight children, two of whom are left-handed, but no other abnormality was noted. No neurological abnormality was detected, and the psychiatrist and social worker found no abnormality in the patient or his background.

He was quiet and hesitant in speech, but quick on performance tests. Bellevue equivalent scores were: digit span, 6 ; arithmetic, 7 ; similarities, 11 ; vocabulary, 8 ; picture arrangement, 14 ; picture completion, 14 ; block designs, 12 . He managed to read the first half of Schonell's R2, with considerable assistance, very poorly, but answered all the questions correctly. On the Phi Test he saw no apparent movement on near fixation, and only occasionally reported some movement, left or right, on far fixation.

Case 2 (N.H.8877). -A schoolboy, aged 13 years and 7 months, was first seen three years ago, on account of reading disability. No physical abnormality was noted. His elder brother had no reading disability. At that time the patient "reversed" almost every word he tried to read.

He was neat, emphatic, and self-assured. Bellevue scores were : digit span, 7 ; arithmetic, 7 ; similarities, 8 ; vocabulary, 7 ; picture arrangement, 8 ; picture completion, 12; block designs, 7 ; digit symbol, 4 . He read and answered Schonell's R2 at the 8-year level, and made reversals only on R7. Apparent movement was intermittent, in either direction, on both fixations.

Case 3.-A builder's labourer, aged 28, was first seen three years ago on account of reading disability, from which he had suffered since his schooldays. Following a closed head injury he had been under treatment for anxiety symptoms, but had no physical abnormality.

He had a new house and opportunity for gardening, and his psychiatric state had improved considerably. His wife had been trying to help him with reading and

* Information, comprehension, and object assembly were omitted.

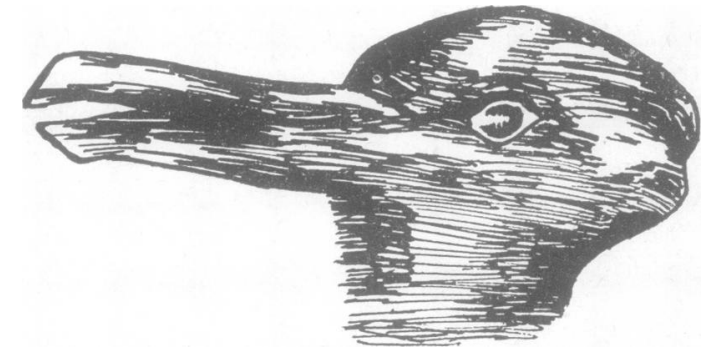

Fig. 2.-Jastrow's ambiguous figure.

writing. Bellevue scores were: digit span, 4 ; arithmetic, 7 ; similarities, 7 ; vocabulary, 7 ; picture arrangement, 6 ; picture completion, 10 ; blocks, 10 ; digit symbol, 8. He could not even read letters accurately, though he made no reversals. Apparent movement was seen consistently on near fixation, and intermittently on far fixation, always to the right.

Case 4 (N.H.14903). - A schoolboy, aged 10 years and 3 months, was admitted to hospital because of a history of a fall, with a small occipital laceration but no loss of consciousness, five years previously. There was no physical abnormality; the E.E.G. was "probably within normal limits for this age, although perhaps rather less organized than is usual ".

$\mathrm{He}$ was alert and cheerful. Bellevue scores were: digit span, 3 ; arithmetic, 1 ; similarities, 7 ; vocabulary, 5 ; picture completion, 8 ; blocks, 4 . He made a number of reversals in reading and writing, but managed to read the first half of Schonell's R2 and answered all the questions correctly. Apparent movement was reported intermittently, in either direction, on near fixation, and predominantly to the right on far fixation.

Case 5 (N.H.12809). - A schoolboy, aged 13 years and 9 months, was admitted to hospital on account of his backwardness and mildly delinquent behaviour. There was no physical abnormality; air-encephalography showed no evidence of cerebral atrophy or hydrocephalus; an E.E.G. had had some unusual features, but on the whole was " acceptable at this age".

He was quiet and rather apprehensive, but cooperated well on testing. Bellevue scores were : digit span, 6 ; arithmetic, 6 ; similarities, 5 ; vocabulary, 6 ; picture arrangement, 9 ; picture completion, 11 ; blocks, 11 ; digit symbol, 4. He read the first half of Schonell's R2 with nine errors very slowly, but answered all the questions correctly, and made reversals only on R7. Very little apparent movement was reported, either way.

Case 6 (N.H.18230). - A transport depot worker, aged 15 years and 5 months, was first seen two years ago, on account of his retardation. There was no physical abnormality, and although there had been inter-parental trouble at home, all the other six children (one lefthanded) could read and write.

$\mathrm{He}$ had a stammer, but was alert and cheerful. Bellevue scores were: digit span, 7; arithmetic, 7 ; 
similarities, 8 ; vocabulary, 7 ; picture arrangement, 11 ; picture completion, 14 ; blocks, 10 ; digit symbol, 7. He read and answered Schonell's R2 at the 9-year level, and made a reversal only on R7. Apparent movement was not reported on near fixation, but was seen simultaneously in both directions on far fixation.

Case 7 (N.H.22351).-A schoolboy, aged 10 years and 4 months, attended the hospital on account of epilepsy. There were no abnormal physical signs, but his scholastic retardation was noted. The E.E.G. was complex but consistent with idiopathic epilepsy.

He was quiet and economical of words, but at the same time appeared at ease and cooperated on the tests. On the Terman-Merrill scale his mental age was 8 years and 3 months, with early failures on verbal items ; on Kohs' block test it was 12 years and 11 months. He made no reversals. Apparent movement was occasionally seen, either way, on near fixation ; and predominantly to the right on far fixation.

Case 8 (N.H.24615). - A schoolboy, aged 11 years and 2 months, attended on account of reading disability. No physical or psychiatric abnormality was found.

He was cheerful and cooperative. Bellevue scores were : digit span, 6 ; arithmetic, 9 ; similarities, 11 ; vocabulary, 8 ; picture arrangement, 10 ; picture completion, 10 ; blocks, 10 ; digit symbol, 6 . He made reversals in reading but not in writing. He reported hardly any apparent movement, either way, on both fixations.

Case 9 (N.H.30319).-An engine-fitter, aged 31, attended on account of headaches following a slight head injury at football, but giving a history of reading disability since his school-days. There was no physical abnormality and a radiograph and E.E.G. were normal.

On testing, there was no evidence of dysphasia or organic deterioration. Bellevue scores were: digit span, 6 ; arithmetic, 6 ; similarities, 6 ; vocabulary, 8 ; picture arrangement, 7 ; picture completion, 14 ; blocks, 9 ; digit symbol, 7. He made one reversal in writing, and three on Schonell's R7. He reported no apparent movement on either fixation.

Case 10 (N.H.31000). - A man, aged 20, at the age of 16 had been certified under the Mental Deficiency Acts, and since then had been detained in an institution. No physical or psychiatric abnormality was found: the E.E.G. was reported as being " borderline" at his age.

He was, perhaps understandably, rather anxious at the beginning of the tests, but became more confident as he found he could do them. Bellevue scores gave : digit span, 7 ; arithmetic, 7 ; similarities, 8 ; vocabulary, 6; picture arrangement, 12 ; picture completion, 14 ; blocks, 15 ; digit symbol, 8 . He made no reversals in reading or writing. He reported no apparent movement on either fixation.

Case 11 (N.H.32010).-An upholsterer, aged 34, attended on account of his reading disability. There was no physical or psychiatric abnormality.

He was short, slightly built, and appeared to be a little nervous about the examination, but became more confident on performance tests. Bellevue scores were : digit span, 6 ; arithmetic, 3 ; similarities, 10 ; vocabulary, 9 ; picture arrangement, 7 ; picture completion, 9; blocks, 11; digit symbol, 7. He made some reversals on Schonell's R7. Apparent movement was reported very occasionally, largely to the right, on both fixations, and was once reported as " both ways".

Case 12 (N.H.33864).-A schoolboy, aged 11 years and 3 months, was admitted to the hospital for investigation of a possible relation between a chronic left otitis and mastoiditis and his scholastic retardation. There was, however, no physical evidence of this : a radiograph of the skull did not indicate spread of infection. An E.E.G. was asymmetrical but "within normal limits for the age"; and audiometry showed normal hearing in the right ear.

He was a quiet, shy little boy, but applied himself enthusiastically to the tests. Bellevue scores were : digit span, 7 ; arithmetic, 7 ; similarities, 8 ; vocabulary, 6 ; picture arrangement, 10 ; picture completion, 10 ; blocks, 12 ; digit symbol, 5 . He read and answered Burt's Test 5 at the 9-year level, but made no reversals. He reported no apparent movement on either fixation.

\section{Results}

The responses of normal subjects on the Phi Test have been described in some detail by Jasper, who examined 77 adults, and by Jasper and Raney, with 43 school-children. In the present study, 12 normal subjects (i.e. with no reading disability) of ages ranging from 9 to 25 years, but not otherwise equated with the patients, were tested, and their responses were similar to those of the subjects tested by Jasper and Raney. All except one reported consistent or predominantly one-sided apparent movement within eight minutes of beginning each phase of the test, and two of the subjects, besides reporting unilateral apparent movement, also reported occasions on which the central light appeared to "split", and jumped to both sides simultaneously. Four of the subjects were shown Jastrow's figure, and all reported that it looked like a bird or a duck.

The results of the 12 patients with reading disability are summarized in Tables I and II. It will be seen from Table I that only three of the patients perceived enough consistent apparent movement to suggest the dominance of one hemisphere, and of these only one (Case 3 ) reported the phenomenon with anything like normal definition. Two patients (Cases 6 and 11) reported the occasional appearance of the central light "splitting". At the same time, while the majority (nine) of the patients showed some tendency to " reversal" either of letters or of Jastrow's figure, this did not appear to bear any consistent relationship to handedness, eyedness, cross-dominance, or to the type of response on the Phi Test. 
TABLE I

RESULTS IN PATIENTS WITH READING DISABILITY

\begin{tabular}{|c|c|c|c|c|c|c|}
\hline \multirow{2}{*}{ Case } & \multicolumn{2}{|c|}{ Preference } & \multirow{2}{*}{$\begin{array}{c}\text { Rever- } \\
\text { sals* }\end{array}$} & \multirow{2}{*}{$\begin{array}{c}\text { Jastrow's } \\
\text { Figure }\end{array}$} & \multicolumn{2}{|c|}{ Apparent Movement } \\
\hline & Hand & Eye & & & Direction & Dominance \\
\hline 1 & $\mathbf{R}$ & $\mathbf{R}$ & 0 & Bird & $\begin{array}{l}\text { Very little, right } \\
\text { and left }\end{array}$ & Indefinite \\
\hline 2 & $\mathbf{L}$ & $\mathbf{L}$ & + & Rabbit & $\begin{array}{l}\text { Very little, right } \\
\text { and left }\end{array}$ & Indefinite \\
\hline 3 & $\mathbf{R}$ & $\mathbf{R}>\mathbf{L}$ & $\mathbf{0}$ & Rabbit & $\begin{array}{l}\text { Predominantly } \\
\text { right }\end{array}$ & $\begin{array}{l}\text { L. hemi- } \\
\text { sphere }\end{array}$ \\
\hline 4 & $\mathbf{R}$ & $\mathbf{L}$ & ++ & 一 & $\begin{array}{l}\text { Intermittent near : } \\
\text { but right far }\end{array}$ & $\begin{array}{l}\text { L. hemi- } \\
\text { sphere } \\
\text { or L.eye }\end{array}$ \\
\hline 5 & $\mathbf{R}$ & $\mathbf{R}$ & + & Duck & $\begin{array}{l}\text { Very little, right } \\
\text { and left }\end{array}$ & Indefinite \\
\hline 6 & $\mathbf{L}$ & $\mathbf{R}$ & + & Duck & $\begin{array}{l}\text { None near : both } \\
\text { far }\end{array}$ & None \\
\hline 7 & $\mathbf{R}$ & $\mathbf{L}$ & 0 & - & $\begin{array}{l}\text { Right on far } \\
\text { fixation }\end{array}$ & $\begin{array}{l}\text { L. hemi- } \\
\text { sphere } \\
\text { or L.eye }\end{array}$ \\
\hline 8 & $\mathbf{R}$ & $\mathbf{R}$ & ++ & Rabbit & $\begin{array}{l}\text { Very little, right } \\
\text { and left }\end{array}$ & Indefinite \\
\hline 9 & $\mathbf{R}$ & $\mathbf{R}$ & + & - & None & None \\
\hline 10 & $\mathbf{R}$ & $\mathbf{L}$ & $\mathbf{0}$ & - & None & None \\
\hline 11 & $\mathbf{L}$ & $\mathbf{R}$ & + & - & A little, right & $\begin{array}{l}\text { L. hemi- } \\
\text { sphere }\end{array}$ \\
\hline 12 & $\mathbf{R}$ & $\mathbf{R}$ & $\mathbf{0}$ & Rabbit & None & None \\
\hline
\end{tabular}

*+ signifies reversals shown only on Schonell's $\mathbf{R 7}:++$ signifies reversals shown more frequently.

TABLE II

RESULTS IN PATIENTS WITH READING DISABILITY

\begin{tabular}{c|c|c|c|c|c|c}
\hline Case & $\begin{array}{c}\text { Chrono- } \\
\text { logical } \\
\text { Age }\end{array}$ & $\begin{array}{c}\text { Mental } \\
\text { Age (Non- } \\
\text { verbal) }\end{array}$ & $\begin{array}{c}\text { Reading } \\
\text { Age }\end{array}$ & $\begin{array}{c}\text { Writing } \\
\text { Age }\end{array}$ & $\begin{array}{c}\text { Rever- } \\
\text { sals* }\end{array}$ & $\begin{array}{c}\text { Memory } \\
\text { for } \\
\text { Designs } \dagger\end{array}$ \\
\hline 1 & 17 & $>15 \cdot 6$ & 8 & 7 & 0 & - \\
2 & 14 & 11.9 & 9 & 7 & + & ++ \\
3 & 28 & $12 \cdot 7$ & $<5$ & 0 & 0 & ++ \\
4 & 10 & 10.3 & 6 & 6 & ++ & + \\
5 & 14 & 12.9 & 7 & 7 & + & ++ \\
6 & 15 & $>15.6$ & 8 & 7 & + & ++ \\
7 & 10 & 12.11 & 6 & 6 & 0 & 0 \\
8 & 11 & 13.0 & 7 & 6 & ++ & ++ \\
9 & 31 & 13.6 & 10 & 7 & + & ++ \\
10 & 20 & $>15.6$ & 12 & 7 & 0 & ++ \\
11 & 34 & 12.7 & 6 & 6 & + & 0 \\
12 & 11 & 13.6 & 10 & 8 & 0 & ++ \\
\hline
\end{tabular}

$*+$ and ++ are as in Table $\mathbf{I}$.

++ signifies a pass at the 9-year level $;+$ signifies a pass at the 11-year level.

Table II indicates the discrepancies between the patients' mental ages (on the performance half of the Bellevue scale) and their reading and writing achievements. It will be seen that the extent of these does not appear to be related to the incidence of reversals. The table also records the good performance of the majority of the patients on the visual retention test.

\section{Discussion}

The cases reported conform to the usual description of the syndrome of specific dyslexia*; their visual perception was normal (cf. Eames, 1948), as was retention of visual material (cf. Fildes, 1921), but they showed a reading retardation of three or more years in comparison with their mental age as measured on non-verbal tasks, and a number of them showed a tendency to reversal of letters, syllables, or of an ambiguous figure. An additional defect, which has been studied in considerable detail by Fildes and noted also by Orton and by Wolfe (1941), is the difficulty shown by these patients in " repicturing or rebuilding in the order of presentation sequences of letters, of sounds, or of units of movement" (my italics) ; a difficulty in acquiring series (Orton, 1937). The present group of patients showed this in their relatively poor digit span scores.

The coincidence of a tendency to reversal and of a difficulty in acquiring series may not, on the face of it, seem an unexpected finding, but its theoretical significance lies in the fact that, in Orton's view, it is the tendency to reversal which disturbs the acquisition of series, and arises, according to him, from a failure to elide the mirror-image engrams in the non-dominant hemisphere. The significance of this tendency to reversal has, however, been questioned by a number of investigators. Thus Schonell $(1940,1941)$ observed that many of his cases of specific dyslexia, particularly older ones, showed no tendency to reversal, and Gilkey and Parr (1944) have shown that, among normal schoolchildren, a tendency to reversal is not inconsistent with superior scholastic achievement. In the present study, the evidence does not confirm Orton's observations $(1937$, p. 151) that the number of errors by reversal tends to correlate with the individual amount of retardation in reading. In fact, only two cases (Nos. 4 and 8) showed reversals in the course of attempts at normal reading and writing; five showed them only on a specially designed test; and five showed no reversals at all, although two of these " reversed" the ambiguous figure. It seems that the tendency to reversal, although frequent, cannot be regarded as the cause of the difficulty in acquiring sequences. On the other * Case 3 had also frank psychiatric symptoms, Case 7 had idio-
pathic epilepsy, and Case 12 a chronic left otitis and mastoiditis pathic epilepsy, and Case 12 a chronic left otitis and mastoiditis
but none of these was considered a primary cause of the dyslexia. 
hand, this tendency, and, in the present group of patients, perception of an ambiguous figure in a right-to-left direction, may be considered as an expression of this series-disability with material which may be seen in a right-left as well as a leftright direction : as far as direction of gaze is concerned, they may be said to be looking " at random." As the dyslexic grows older he may overcome this tendency to reversal, as Schonell has observed, but is left with a primary disability in acquiring sequences which hinders his acquisition of reading and writing.

At the same time the evidence from the Phi Test does not appear to support the second part of Orton's theory that specific dyslexia arises from "a confusion in cerebral dominance" ; that these cases are ones " in whom the dominance for some functions is in one hemisphere and for some in the opposite" (1943). It has been demonstrated that in normal readers the perception of apparent movement is predominantly in the half-field of vision which is related to the dominant hemisphere ; and, although it cannot be claimed that this perception be directly related to the ability of a hemisphere to acquire reading and writing patterns, the consistency of the observation, with right- and left-handed subjects, suggests that it is an expression of what Jasper termed " unilaterality in general neural organisation". If, then, dominance in cases of specific dyslexia were in fact established in the opposite hemisphere, it might be expected that apparent movement would be perceived in the opposite half-field; or were it "confused" or equally distributed in both hemispheres, the apparent movement might alternate (which it did in at the most three patients, Nos. 1, 2, and 5) or occur simultaneously in both directions (occasionally in Cases 6 and 11). The observation that in specific dyslexics, as in many of Jasper's stutterers, little or no apparent movement is perceived, suggests that in these patients the neurophysiological organization corresponding to "dominance" has not been established in a normal fashion in either hemisphere.

In conclusion, it must be emphasized that this study with the Phi Test can only be regarded as a preliminary approach to the question of hemispheral dominance in visual functions, and in association with reading disability. Even if no more effective indicator of cerebral dominance in these functions is evolved, a number of problems remains to be solved. Before an attempt can be made at answering the question of structural basis of this disability, Phi Test investigations will be needed of cases of acquired lesions and areas of dysfunction in the dominant hemisphere, and the relation of dominance to direction of gaze may require a study of subjects from cultures in which the reading-direction is from right to left.

\section{Summary}

By comparing the extent to which apparent movement is seen in the two half-fields of vision, Jasper and Raney's Phi Test enables an estimate to be made of hemispheral dominance in this function, and close agreement has been found between the hemisphere indicated on this test and that indicated by the subject's handedness.

Twelve cases of specific reading disability have been examined with this test: the noteworthy feature of their performance was that the majority of the patients reported little or no apparent movement (agreeing with Jasper's earlier experience with stutterers). The evidence from this test, and from the patients' performances in reading and writing, does not support Orton's theory that the basis of specific dyslexia is a "confusion in cerebral dominance ", with failure to elide " antitropic records" in the minor hemisphere. It suggests rather that in these cases the neurophysiological organization corresponding to dominance has not been normally established in either hemisphere.

I am indebted to members of the staff of the National Hospital and to Drs. D. Whittaker and H. V. Dicks for permission to make reference to their cases, and to Professors R. C. Oldfield and O. L. Zangwill for their encouragement and advice.

\section{REFERENCES}

Blau, A. (1946). “The Master Hand." Amer. Ortho-psychiat. Ass. Res. Monogr. No. 5.

Burt, C. (1947). " Mental and Scholastic Tests", 2nd ed. London. - (1950). " The Backward Child", 3rd ed. London.

Buxton, C. E., and Crosland, H. R. (1937). Amer. J. Psychol., 49, 458. Eames, T. H. (1948). Amer. J. Ophthal., 31, 713.

Fildes, L. G. (1921). Brain, 44, 286.

Giles, L. G. (1921). Brain, 44, 286.4 . Hallgren, B. (1950). Acta Psychiat., Kbh., Suppl. No. 65.

Harris, A. J. (1947). “Harris Tests of Lateral Dominance." New York.

Hinshelwood, J. (1917). "Congenital Word-Blindness." London.

Jasper, H. H. (1932). Psychol. Monogr. (No. 194), 43, No. 1, p. 72.

-7 , and Raney, E. T. (1937). Amer. J. Psychol., 49, 450.

Macmeeken, M. (1939). "Ocular Dominance in Relation to Developmental Aphasia." London.

Orton, S. T. (1937). "Reading, Writing and Speech Problems in Children." London.

(1942). Arch. Neurol. Psychiat. Chicago, 47, 1064.

(1943). Arch. Ophthal., Chicago, 30, 707.

Ministry of Education (Pamphlet No. 18). (1950). "Reading Ability." H.M. Stationery Office, London.

Schonell, F. J. (1940). Brit. J. educ. Psychol., 10, 227.

- (1941). Ibid., 11, 20.

(1948). "Backwardness in the Basic Subjects", 4th ed. Edinburgh.

Selzer, C. A. (1933). "Lateral Dominance and Visual Fusion." Harv. Monogr. Educ. No. 12

Stevens, H. C., and Ducasse, C. J. (1912). Psychol. Rev., 19, 1.

White, A. M., and Dallenbach, K. M. (1932). Amer. J. Psychol., 44, 175 .

Wile, I. S. (1942). Arch. Ophthal., Chicago, 28, 780.

Wolfe, L. S. (1941). J. genet. Psychol., 58, 45 and 57. 